\title{
In-Season vs. Out-of-Season Academic Performance of College Student-Athletes
}

\author{
Brianna M. Scott \\ National Collegiate Athletic Association \\ Thomas S. Paskus \\ National Collegiate Athletic Association \\ Michael Miranda \\ State University of New York-Plattsburgh \\ Todd A. Petr \\ National Collegiate Athletic Association \\ John J. McArdle \\ University of Southern California
}

\begin{abstract}
There is a commonly held belief within the intercollegiate athletics community that student-athletes perform better academically during their season of athletics competition than they do outside the season of competition. The thought is that the structured nature of the playing season leads to more structure in student-athletes' academic lives and better academic performance. However, it is difficult to find empirical studies supporting this belief. A series of three studies was conducted to assess whether there is a difference in the grade-point average and credits earned of student-athletes in their season of competition vs. their off-season. These three studies are distinguished by NCAA membership division (Division I, Division II or Division III) and the specific nature of the data available in each of those divisions. The Division III study served as a pilot and examined over 3,000 student-athlete records at eight schools. The Division II study included nearly 12,000 student-athletes at 92 schools, and the Division I study involved analysis of a census of Division I student-athletes at over 325 colleges and universities followed term-by-term for up to four years. The separate divisional studies came to similar conclusions. Generally, the academic performance of student-athletes was shown to be better outside the season of competition than during the season - contrary to the conventional wisdom. The negative in-season effects were stronger in sports known to have high in-season time demands (e.g., Division I football, baseball and softball) and among student-athletes who entered college less well prepared academically.
\end{abstract}

Scott, Paskus, and Petr are with NCAA Research, PO Box 6222, Indianapolis, IN, 46206; Miranda is with the State University of New York-Plattsburgh, Library, 2 Draper Ave., Plattsburgh, NY, 12901; McArdle is with the University of Southern California, Psychology, SGM 711, 3620 South McClintock Ave., Los Angeles, CA, 90089-1061. 
Although many positive effects of college sports on the student-athlete participants have been noted (e.g., Aries, McCarthy, Salovey, \& Banaji, 2004; Robst \& Keil, 2000), it has been suggested that the competing demands of high expectations in the classroom and on the playing field may lead to academic difficulties for some student-athletes. Certainly much research has documented graduation rate gaps between student-athletes in certain sports (e.g., in men's basketball, baseball and football) and other student-athletes (Long \& Caudill, 1991; NCAA, 2007). This research extends to many different types of institutions across all three NCAA divisions (see Shulman \& Bowen, 2001; Bowen \& Levin, 2003). However, it is less clear whether graduation rate gaps are due simply to differential academic preparation or also reflect some aspect of the demands of competing in college athletics.

Do those of us involved in athletics underestimate the impact that the demands of being a high-level athlete have on college academic success? An interesting example relates to a commonly held belief within the college athletics community on the nature of in-season vs. out-of-season academic performance. The authors have often heard athletics personnel insist that due to the structured nature of the playing season, many student-athletes perform better academically in-season than they do during the less structured off-season. Very little empirical evidence has been produced to back up this assertion. Frost (2001) found that Division III student-athletes in soccer and lacrosse did have higher grade point averages in-season vs. out-of-season, but the sample was not representative of all student-athletes, especially those in high-profile sports like football. Other research (Paskus, 2008) suggests that such a finding is not in line with expectations based on the in-season time demands of college sports and the stress involved in balancing the two for some students (e.g., perhaps students who are less prepared for college academic demands). In addition, Maloney \& McCormick (1993) found that the relatively poor performance of student-athletes in high-profile sports (in comparison with nonathlete students) was isolated to the playing season; these student-athletes tended to fare better than their nonathlete counterparts in the off-season.

The current study tests whether academic performance as measured by grade point average and credit hour attainment is helped or hurt by the enhanced demands that most student-athletes experience during the portion of their academic year when they are most heavily involved in athletics competition. As a result of some new NCAA data collection initiatives, especially in Divisions I and II, the authors were able to examine term-by-term academic performances for student-athletes in the majority of sports in which the NCAA holds a championship event. Although a nonathlete comparison group was not available, the authors were able to compare student-athletes in the "high profile" sports of men's basketball, football and baseball to student-athletes in other (what we often term "Olympic") sports, a comparison that has merit due to the similarity of academic performance between student-athletes in Olympic sports and college students generally (Maloney \& McCormick, 1993). The seasonal effect on academic performance of college student-athletes was examined to answer two primary questions:

1. Do credit attainment and grade point average (GPA) fluctuate in-season to out-of-season for college student-athletes?

2. Are student-athletes in certain sports or with certain academic backgrounds (e.g., low academic preparation) more prone to seasonal academic effects? 
First, data were examined for a small sample of Division III student-athletes in select sports. After finding interesting results in Division III, two additional studies were subsequently conducted: one for Division II and one for Division I. The data from Divisions II and III were cross-sectional (one year of measurement) and did not allow for certain advanced statistical analyses (e.g., longitudinal modeling), but did provide novel descriptive data. The Division I study was based on a four-year longitudinal census of student-athletes who competed in Division I between 2003-04 and 2006-07. Thus, we were able to study the effect in more nuanced ways, including intraindividual change models using hierarchical linear modeling (HLM) techniques, to assess the cyclical nature of the data.

\section{Pilot Study: Division III Student-Athletes}

\section{Method}

Division III institutions do not have a mandatory or voluntary submission system for academic data. Thus, to gather term-by-term academic data, the Faculty Athletics Representatives (FARs), faculty members who serve as points of contact between their campuses and the NCAA, at over 400 Division III institutions were contacted by e-mail and invited to take part in this pilot study. Initially, twelve FARs expressed interest in participating, but ultimately data from eight institutions on a semester calendar were used for the study. The eight Division III schools provided data from student-athletes in eleven sports. Women's sports included field hockey, cross country, lacrosse, softball, soccer and volleyball. Men's sports included football, cross country, lacrosse, baseball, and soccer. These sports were chosen for study because intercollegiate competition is limited to either fall or spring semester for each. A dichotomous variable was created to indicate either fall or spring as "in-season" in subsequent analyses. Data from multisport athletes (primarily an issue in cross country / track) and athletes in sports with a winter championship (where competition is split across both semesters) were not collected in order to present a clean initial picture of seasonal academic differences.

FARs in the study were sent an Excel spreadsheet template and asked to supply information on student-athletes for the 2002-03, 2003-04 and 2004-05 academic years once appropriate campus IRB approval was obtained. The FARs either had direct access to the information requested or worked with the campus registrar or other school officials to gather the requested information. FARs then submitted (without personal identification) the following data for each studentathlete playing any of the eleven study sports: sport, sex, fall and spring semester GPA, credits attempted during the fall and spring semesters (in contrast, the Division I and II studies examine credits earned), and cumulative GPA at the end of the academic year. In all, semester GPA was available for 3,143 student records and credits attempted was available on a smaller sample of 2,830 cases due to a clerical discrepancy at one school. Note that some student-athletes appeared multiple times in the database as records were provided separately for each year in an anonymous fashion, precluding the linking of those yearly records into a longitudinal database. This limited nonindependence of sampling was expected to violate an assumption of the statistical test used ( $t$ test), which could result in lower statistical power to detect effects. Given the parameters of this pilot study, it was not 
possible to identify the student-athletes with multiple years of data and adjust the analysis accordingly.

\section{Results}

Paired samples $t$ tests were used to examine the differences in GPA and credits taken in-season and out-of-season. In the broadest analysis, Division III studentathletes were found to have a slightly lower semester GPA in-season than they did out-of-season. Across all cases, the average in-season GPA was 2.93 and the average out-of-season GPA was 3.00, resulting in an average differential of 0.07 , statistically significant at the $p<.01$ level. The findings were similar when analyzed separately for male student-athletes and female student-athletes (0.07 GPA differential for men; 0.06 GPA differential for women). It should be noted that within these selected sports the average GPA for female student-athletes was considerably higher than that for the male student-athletes (3.17-2.78), yet the in-season and out-of-season differences were quite similar. As seen in Table 1, there was also a clear pattern of student-athletes attempting fewer credits during their primary season of competition compared with their off season.

Within sport, student-athletes in men's lacrosse and women's volleyball exhibited the greatest average drop-off in GPA in-season vs. out-of-season, with 0.19 and 0.14 average grade point differentials observed in the respective sports. Men's football ( 0.4 credits less in-season) and women's volleyball ( 0.5 credits less in-season) showed the largest average differences in credits attempted between seasons. Overall, the Division III student-athletes in these select eleven sports achieved slightly lower GPAs and fewer credits attempted in season than they did out of season.

\section{Discussion}

The conventional wisdom within intercollegiate athletics has been that studentathletes perform better academically in-season than out-of-season, primarily because of the structure that the playing season provides in helping studentathletes organize their time and avoid nonacademic distractions. The results from this study revealed that, at least for a small group of Division III institutions, student-athletes tended to have lower GPAs even though they were taking fewer

Table 1 Seasonal Differences in Credits Attempted Among Division III Student-Athletes

\begin{tabular}{lcccc}
\hline & N & $\begin{array}{c}\text { Average in-season } \\
\text { credits attempted (SD) }\end{array}$ & $\begin{array}{c}\text { Average out-of-season } \\
\text { credits attempted (SD) }\end{array}$ & $\begin{array}{c}\text { Average } \\
\text { differential }\end{array}$ \\
\hline All cases & 2,830 & $14.97(2.2)$ & $15.26(2.2)$ & $.29^{*}$ \\
Men & 1,776 & $14.79(2.3)$ & $15.10(2.2)$ & $.31^{*}$ \\
Women & 1,054 & $15.26(2.1)$ & $15.54(2.2)$ & $.28^{*}$ \\
\hline
\end{tabular}

*Indicates statistical significance at $p<.01$ level. 
credits during their playing seasons. Further exploration of these issues was pursued using more extensive data available for student-athletes at Division II institutions.

\section{Study 1: Division II Student-Athletes}

\section{Method}

All Division II schools were invited to participate in a voluntary data collection during the 2005-06 and 2006-07 academic years using the Academic Tracking System (ATS), a web-based software application developed by the NCAA. The software was customized for Division II institutions to track academic performance and outcomes of student-athletes. This application allows users to import academic data for all student-athletes in a particular entering cohort from any of a number of software platforms - most participants did not have to enter additional information by hand. Note that participation in the ATS was voluntary among Division II institutions through 2007 (when the data were collected for this study) but has since become mandatory; the voluntary collection was essentially a process for schools and the NCAA to pilot collection procedures.

Ninety-four of the 293 Division II schools (32\%) participated in this data collection. A logistic regression analysis was used to determine if the participating sample was representative of all Division II institutions by predicting data collection participation from a set of college-level variables. The results showed that participation was not predictable from a college's graduation rate but was predictable from status as a historically black college or university (HBCU) and resource level of the Division II college/university. In other words, the sample participating was similar in academic profile to Division II as a whole but included fewer HBCUs and lower-resourced schools than would be expected in a random sample of Division II colleges and universities. It is believed that the underrepresented institutions did not have all of the necessary resources, including personnel, to participate in the voluntary data collection. This selection issue could impact the generalizability of the findings for Division II, although the representativeness problems were relatively small.

Student-athletes who played in more than one sport were excluded from the analysis since they could reasonably be considered in-season during both semesters (again, primarily an issue among student-athletes participating in both cross country and track). Only semester schools were included for ease of analysis, which reduced the sample from 94 to 92 colleges and universities. In addition, only those student-athletes taking classes during both semesters were included in the analysis. In the end, data from 92 schools and 11,815 student-athletes $(57 \%$ male, 43\% female) from cohorts entering Division II in 2004-05, 2005-06 or 2006-07 were studied. Data from these three cohorts were combined for the analyses due to low sample sizes in certain sports. Given the nature of the data collection, only students in their first three years of college were available for study. Although student-athletes from all Division II sports were included in the aggregate analyses, only 10 men's and 10 women's sports had sufficient numbers for within-sport testing of seasonal effects. The sports included men's baseball, bas- 
ketball, football, golf, ice hockey, lacrosse, soccer, swimming, tennis and wrestling; and women's basketball, crew, field hockey, golf, lacrosse, softball, soccer, swimming, tennis and volleyball. "Winter sports" (e.g., men's and women's basketball) were considered spring sports for this study and Study 2 because the contests considered most important in those sports occur in the spring semester. For example, basketball teams play more regular-season games in the spring and all championship games are played in the spring semester.

\section{Results}

The data from Division II were more complete and included a larger sample than data available in the Division III pilot study discussed previously. However, the results are similar. Paired-samples $t$ tests were used to analyze the differences between student-athletes' in-season vs. out-of-season academic performance. In aggregate across the entire sample, student-athletes tended to have a slightly higher GPA out-of-season than in-season (2.87 vs. 2.83; statistically significant at $p<.01$ although with a small effect size). The relative size of the effect was similar for male (2.67 vs. 2.71) and female (3.05 vs. 3.08) student-athletes.

Within sport, all observed effects indicated either lower academic performance in-season or no performance difference by season. Males in baseball, basketball, lacrosse, soccer and tennis averaged significantly lower GPAs in-season than out-of-season (see Table 2). Similar in-season underperformance was noted for female student-athletes in lacrosse, softball and soccer (Table 3).

Division II student-athletes also tended to show a statistically significant differential between in-season and out-of-season credit hours earned. On average, student-athletes earned 0.4 credits less in-season than out-of-season $(0.3$ credit difference for females, 0.4 for males). Specifically, male student-athletes competing in the higher profile sports of baseball, basketball and football earned significantly more credits out-of-season (Table 4). Division II females in softball, soccer and volleyball all earned fewer credits in-season. Only women golfers and swimmers earned more credits on average in-season than out-of-season (see Table 5).

Data on these student-athletes' academic preparation (such as high school GPA) were not available, so testing whether less academically prepared studentathletes had larger or smaller seasonal differentials was not possible. However, this information was available for Division I student-athletes in Study 2.

\section{Discussion}

Similar to the Division III pilot study results, Division II student-athletes tended to have lower GPAs in-season than out-of-season. A smaller effect in the aggregate in-season vs. out-of-season GPA differential was noted in Division II but may be a result of including winter sports that span both semesters within the Division II study and not the Division III pilot. Within-sport results were statistically significant in a number of men's sports including baseball and basketball. An examination of variation in the seasonal GPAs (e.g., the standard deviation values in the tables) hints that these effects may not be the result of a global shift among student-athletes in a particular sport (as might be indicated by similar standard devia- 


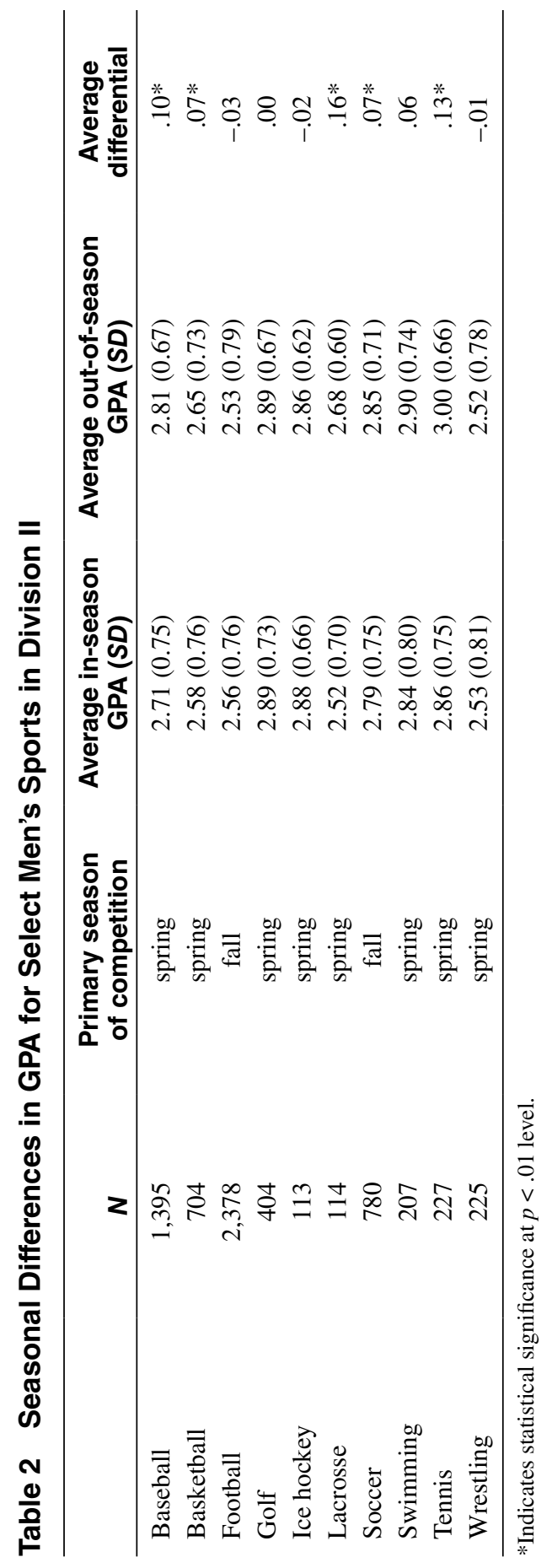




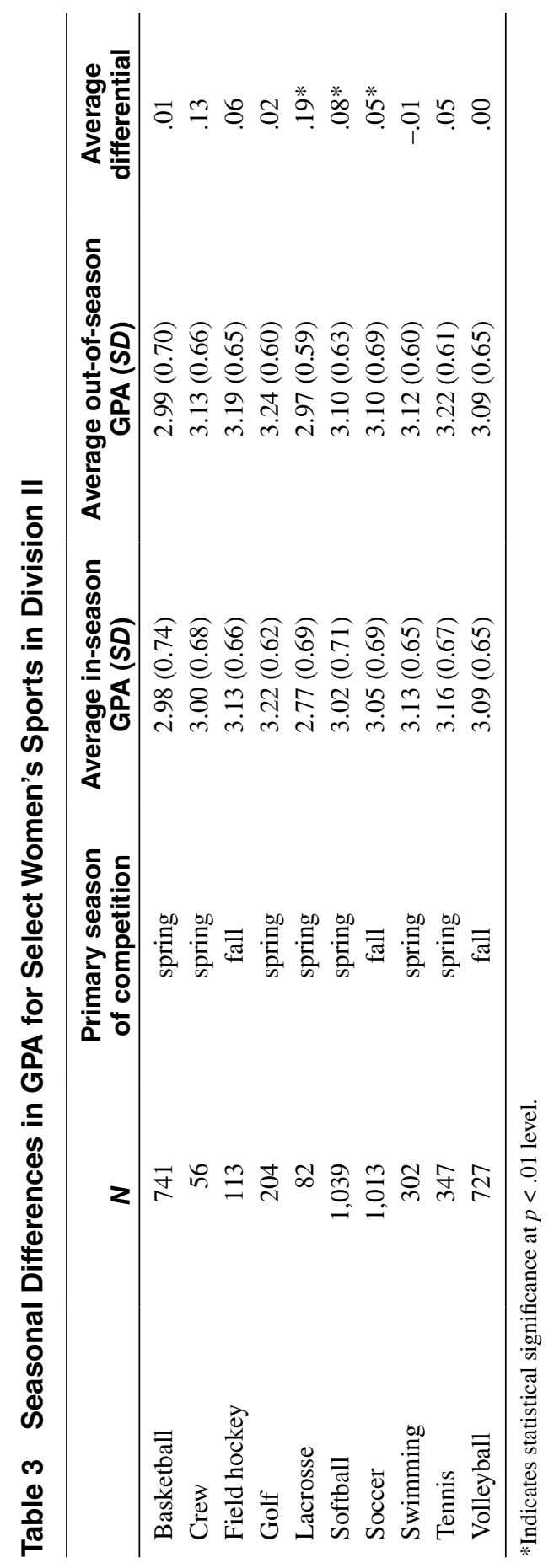




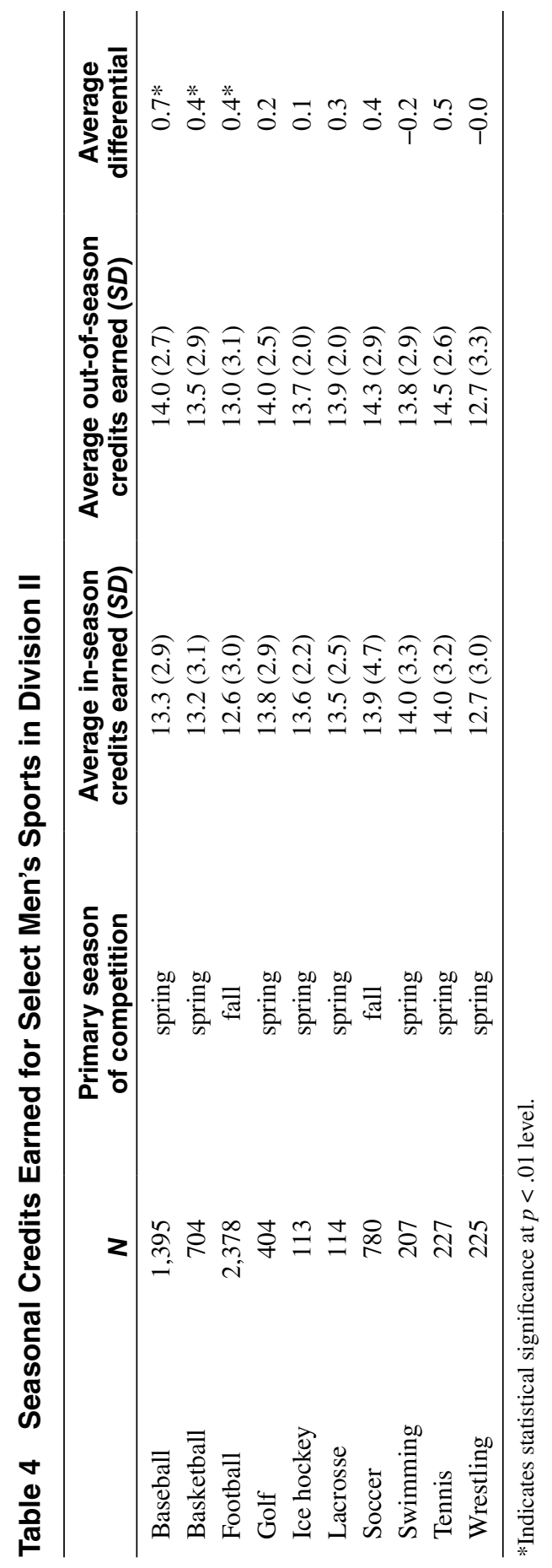




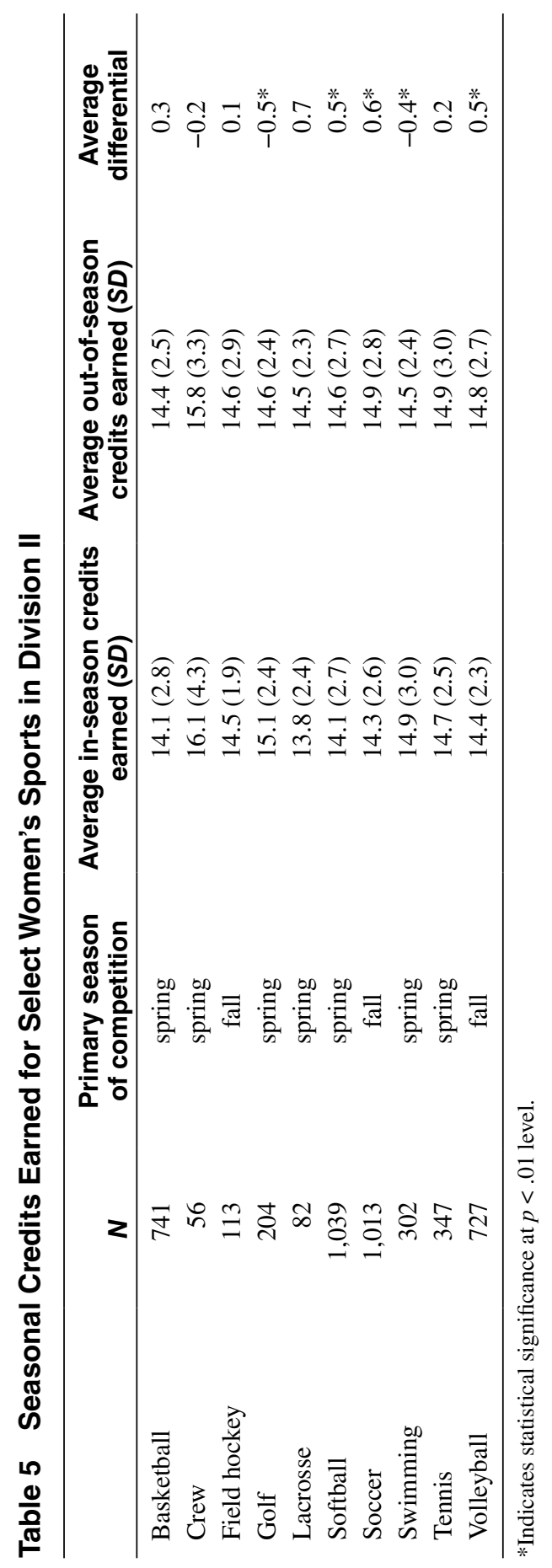


tions in-season and out-of-season) but may relate to a subset of student-athletes within the sport experiencing in-season academic issues (note the larger in-season GPA standard deviations in Table 2).

Also consistent with the pilot study results, the typical Division II studentathlete earned fewer credit hours during their playing season. As with GPA, significant differentials were noted among high profile men's team sports, but also among student-athletes in a number of other men's and women's sports. These results again contradict the conventional wisdom that student-athletes perform better academically in-season than out-of-season. Study 2 examines similar research questions but with longitudinal data from the entire population of Division I institutions.

\section{Study 2: Division I Student-Athletes}

\section{Method}

All Division I institutions provided academic data via a mandatory data submission process using the Division I Academic Performance Program (APP), a webbased software program developed by the NCAA. As a condition of NCAA membership, each Division I school submits term-by-term academic measures (e.g., grade point average, credits attempted, credits earned, retention status, etc.) for all Division I student-athletes who are on some form of athletics aid. Division I schools that do not award athletics aid (e.g., Ivy League institutions) provide academic data on all recruited student-athletes. The data that are submitted by each school are verified by NCAA staff for completeness and accuracy and cleaned for computations required for membership purposes (e.g., calculation of each squad's Academic Progress Rate). For the current study, data were available for all Division I student-athletes who competed at any time within the period from 2003-04 through 2006-07. These data were subset for each analysis to follow as described below.

\section{Results}

Descriptives. Since the descriptive results were similar within each of the four academic years for which data were collected, the first portion of the analysis focuses on student-athletes in college during the most recent academic year with available data (2006-07). To test for seasonal differences in GPA and credits earned, a student-athlete's data were included if he or she took classes both semesters. Student-athletes who competed at an institution on the quarter system were not included. Multisport student-athletes were excluded and by-sport analyses were not undertaken for cross country or track due to the extensive student-athlete crossover in those sports. The descriptive data are also limited to student-athletes in their first three years of college (whether they entered directly from high school or transferred from another institution) due to possible confounds occurring in years four and beyond that are noted in more detail in the longitudinal analyses to follow. In addition, as in Study 1, sports with winter championships (e.g., men's and women's basketball) were considered spring sports for the analysis. The sample size for these preliminary analyses was 50,099 student-athletes. Paired- 
samples $t$ tests were used to assess differences between in-season and out-ofseason GPAs and credits earned.

Overall, student-athletes averaged an in-season GPA that was 0.03 units lower than obtained out-of-season, a small but statistically significant effect. This effect was stronger among males (0.05 GPA-units lower in-season; 2.67 vs. 2.72); differences for females were statistically significant but very small (3.08 in-season vs. 3.09 out-of-season). In aggregate, there was also a statistically significant differential of 0.4 fewer credits earned in-season (differential of 0.5 among males and 0.3 among females).

Tables 6 and 7, which show seasonal grade-point average by sport, highlight several interesting findings. First, males in each of the high-profile sports of baseball, football and basketball performed significantly less well in their coursework in-season. These statistical effects are among the largest seen but are still considered small by traditional statistical standards (e.g., Cohen, 1992). Second, significantly lower in-season GPAs are also seen in men's soccer, women's softball and women's volleyball. Note that all of these sports other than men's basketball have primary competitive seasons limited to one semester or the other. Third, only men's and women's ice hockey and women's swimming showed the opposite pattern with significantly higher GPAs during the season considered in-season in this study. Although the hockey and women's swimming results appear to indicate support for the notion of better academic performance during the competitive season, it should be noted that within Division I teams in both of these winter championship sports begin competitions as early as the first half of October and finish in late March to early April. Thus, a case could be reasonably made that the assignment of spring as in-season for each sport may be faulty.

Among male student-athletes (Table 8), all significant differences in credit hours earned were marked by lower in-season credit accumulation. Particularly noteworthy are the differences in the high-profile men's sports (baseball, basketball and football) and several other men's sports with fall or spring championships (e.g., lacrosse, soccer, tennis, water polo). Student-athletes in women's sports with fall or spring championships tended to earn fewer credits in-season (see Table 9).

All analyses to this point involved the description of seasonal differences in a single academic year. Because complete Division I term-by-term data were available for four consecutive academic years from 2003-2004 through 2006-07, we also were able to examine seasonal cycles in the same students over the course of their academic careers. We chose to subset the data to student-athletes who were freshmen during the 2003-04 academic year to maximize the number of data points for a given cohort of individuals (i.e., 8 time points possible). This also allowed for more parsimonious analyses and ease of interpretation of the longitudinal results. Traditional methods for analyzing longitudinal data (e.g., repeated measures analysis of variance) are not suitable for this analysis because students differ in the number of available data points (for example, eight-semester data are "incomplete" if a student drops out of college before the end of year four). That is, traditional repeated measures techniques require that all participants have data for all time points, which was not the case in the current study. Therefore, we used hierarchical linear modeling to determine whether GPA and credit attainment fluctuate as a function of competition schedule and whether students in certain 


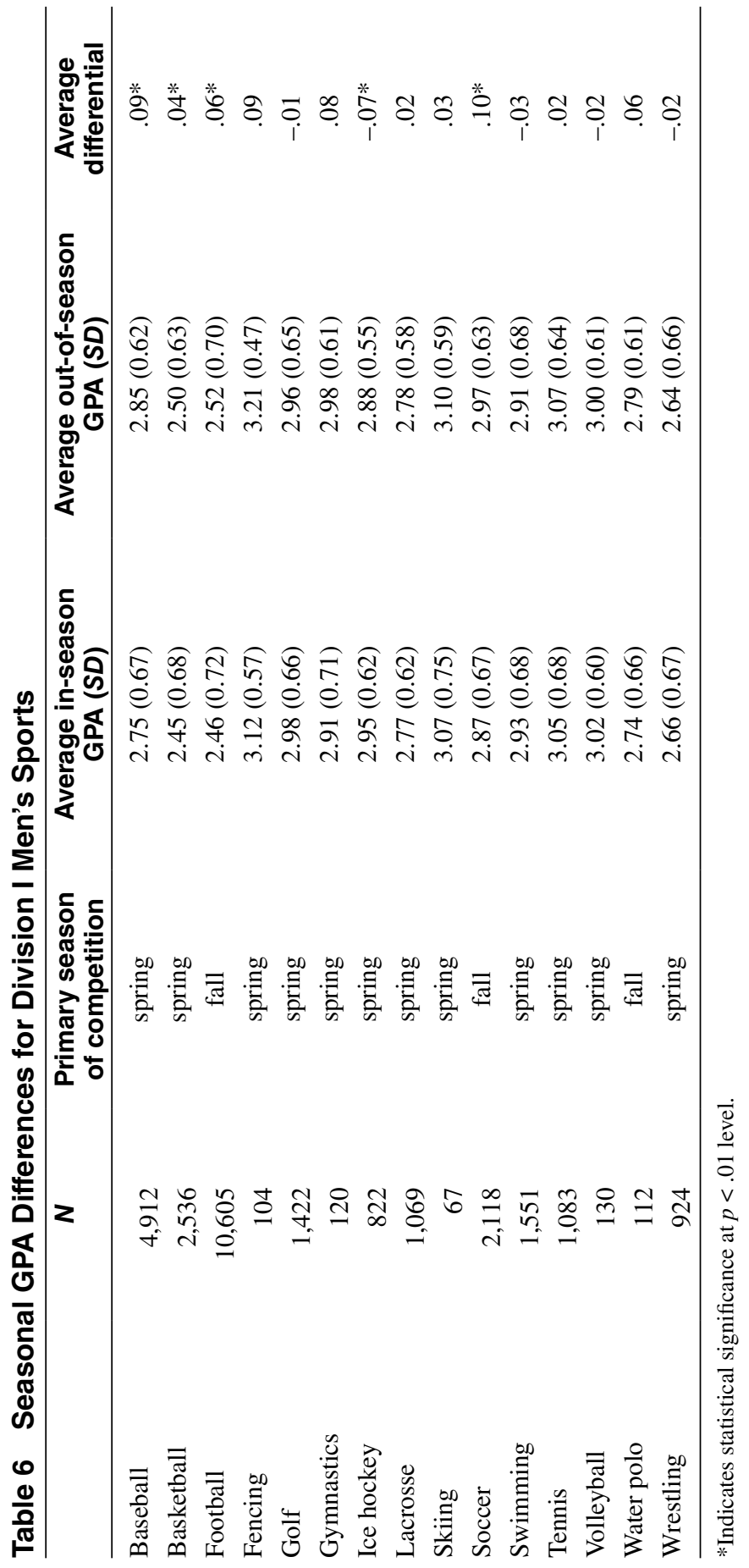




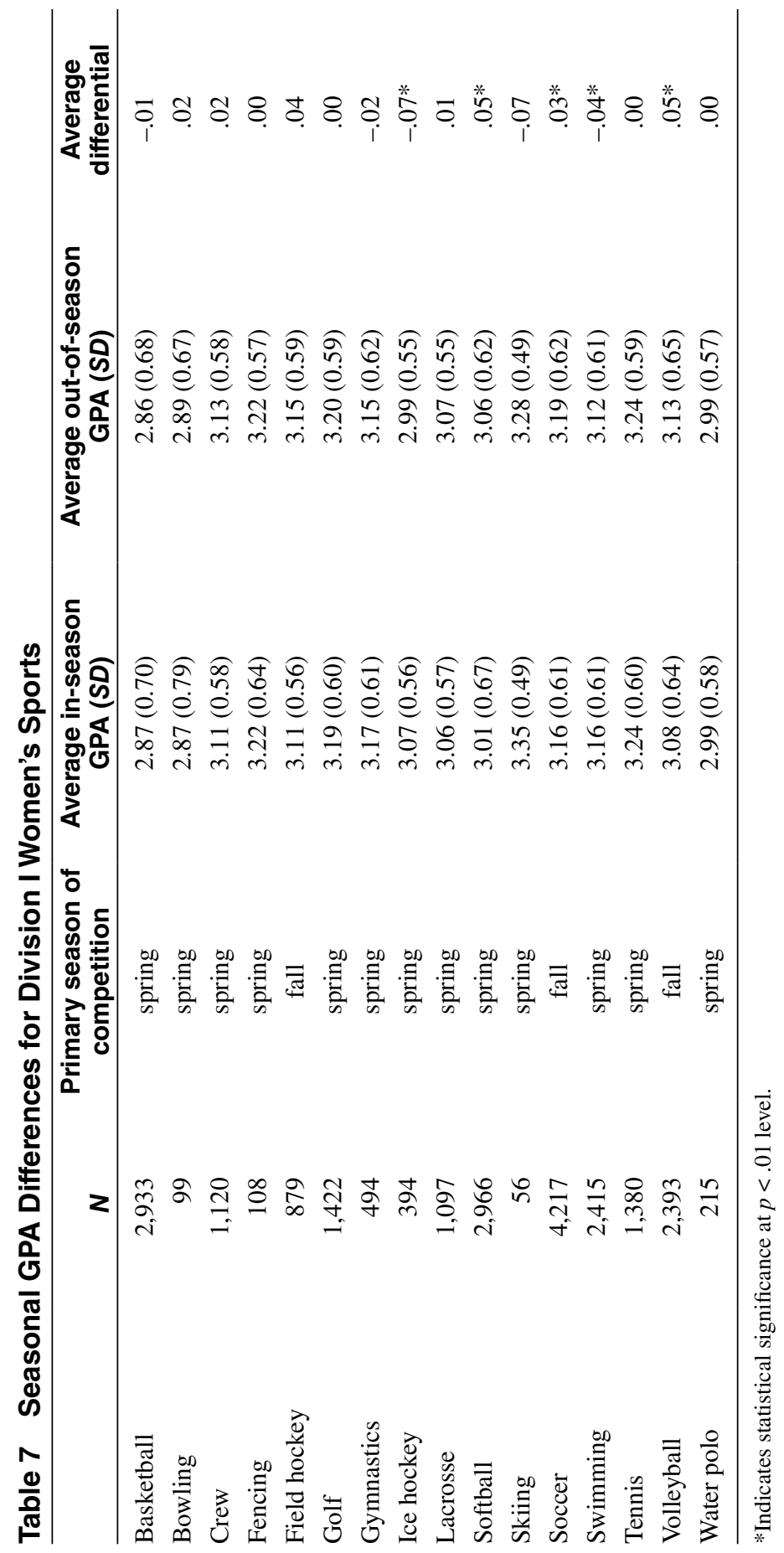




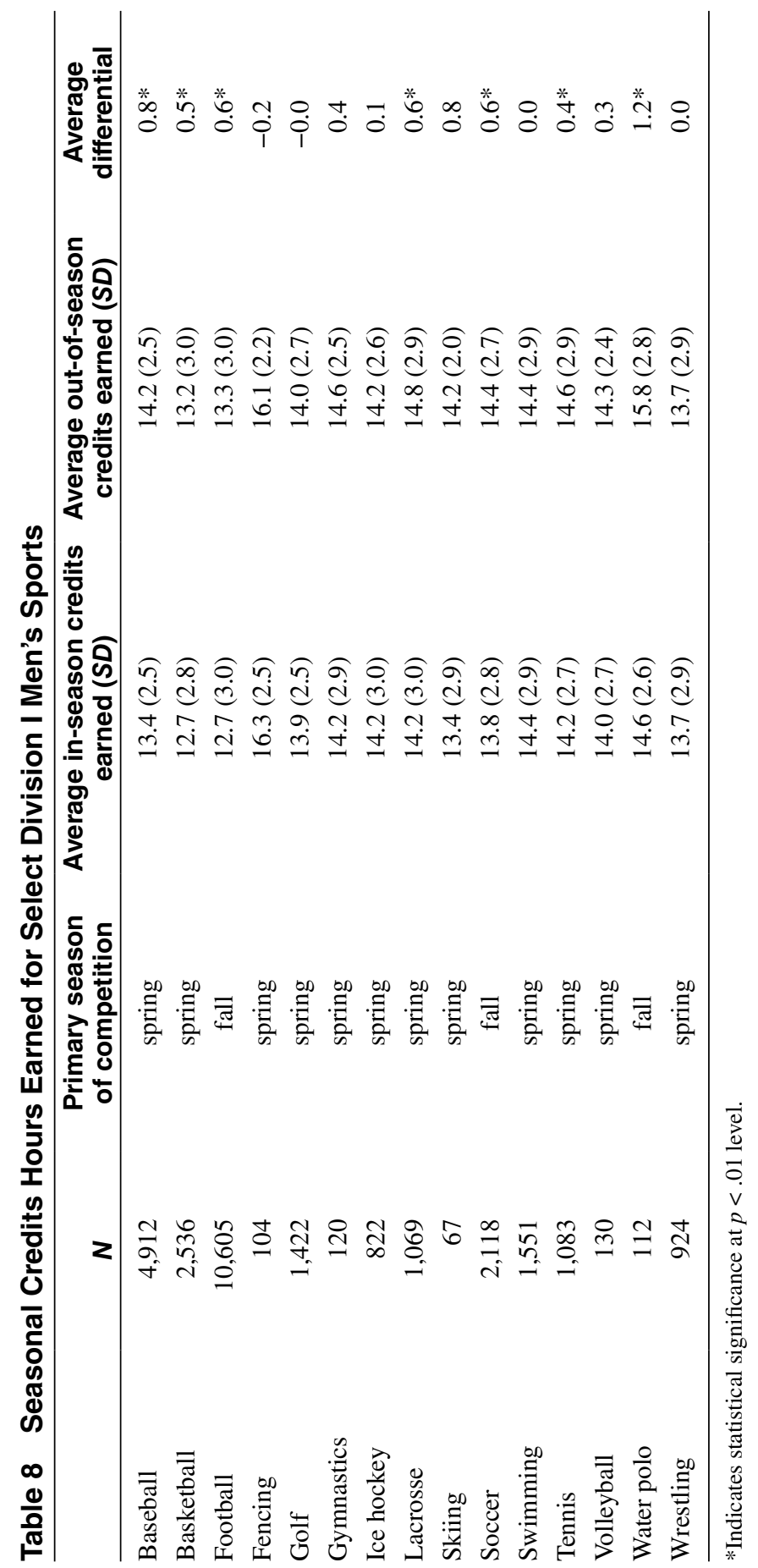




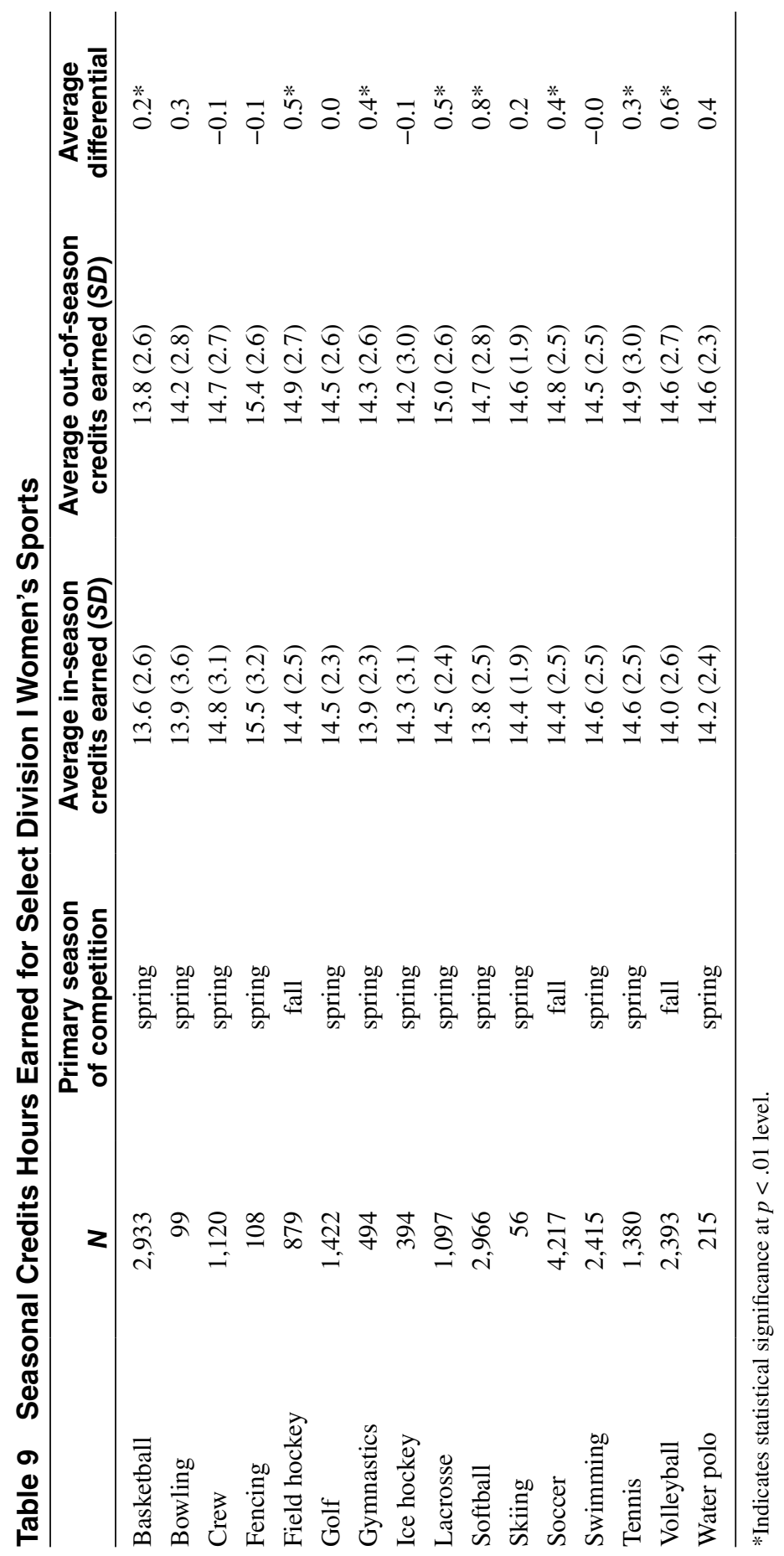


sports or from particular backgrounds (e.g., low academic preparation) are more prone to seasonal academic effects.

Hierarchical linear modeling for the study of change. Hierarchical linear modeling allows for less than complete data from participants and for data collected at nonuniform time points (Bryk \& Raudenbush, 2002; Singer \& Willett, 2003). The term "hierarchical" in this case means that we are first examining the individual change in GPAs or credits earned over time and, on a second level, attempting to predict seasonal effects for GPAs or credits earned if they exist from other student-level variables (Jones, Livson, \& Peskin, 2003; McArdle \& Hamagami, 1994).

Student-athletes who were freshmen in 2003-04 were included in the analyses and were measured during one to eight semesters in college. Those who started as freshmen in 2003-04 but transferred from one Division I institution to another were maintained in the database. There were two notable exclusions of studentathletes from the dataset. Student-athletes who competed for colleges or universities on a quarter academic system and those who competed in more than one sport were excluded from the analyses to better judge the seasonal impact of athletics competition. All models were run using the SPSS MIXED procedure. Whereas each student had been represented by a single row in the original data file, the current modeling required a restructured "person-period" database (e.g., one line for each semester that a student is present; Singer \& Willett, 2003).

Longitudinal models of grade point average. A series of three models was tested to assess the effect of competition season on GPA in a given semester and determine whether other student-level variables relate to a seasonal effect. The first model was a baseline (unconditional) model where semester GPA was predicted by time only (coded 1 through 8 representing sequential semesters in school beginning with freshman fall). The primary purpose of this model was to determine whether GPAs change over the course of a student-athlete's time in college. Subsequent models built upon the baseline model to control for trends in GPA.

The second model added a variable to each person-period record that specified whether the student-athlete's sport was in-season or out-of-season during that term. This model allows for an overall test of in-season effects after controlling for GPA trending. The third model then added variables specified to predict whether high school GPA in core academic classes (HSCGPA) and sport type (high profile vs. men's Olympic vs. women's sports) are related to the in-season effect. That is, if an in-season effect exists, does it vary as a function of these additional variables?

Selected results of the three models are shown in Table 10. The first model indicated that indeed college GPAs tend to trend up by approximately 0.03 grade points $(t(11689)=26.6, p<.01)$ every term that a student is in college. When we control for this trending in the second model, we find that GPAs average 0.06 grade points lower in-season $(t(61625)=17.87, p<.01)$. This is a larger value than found through the prior analysis of the Division I data, likely due to the better control provided by this type of longitudinal analysis. The third model shows that the in-season effect is different as a function of HSCGPA and sport group. The HSCGPA parameter estimate of $-0.036(t(55192)=-5.84, p<.01)$ indicates that the in-season effect is expected to decrease by 0.036 college grade-point units for 


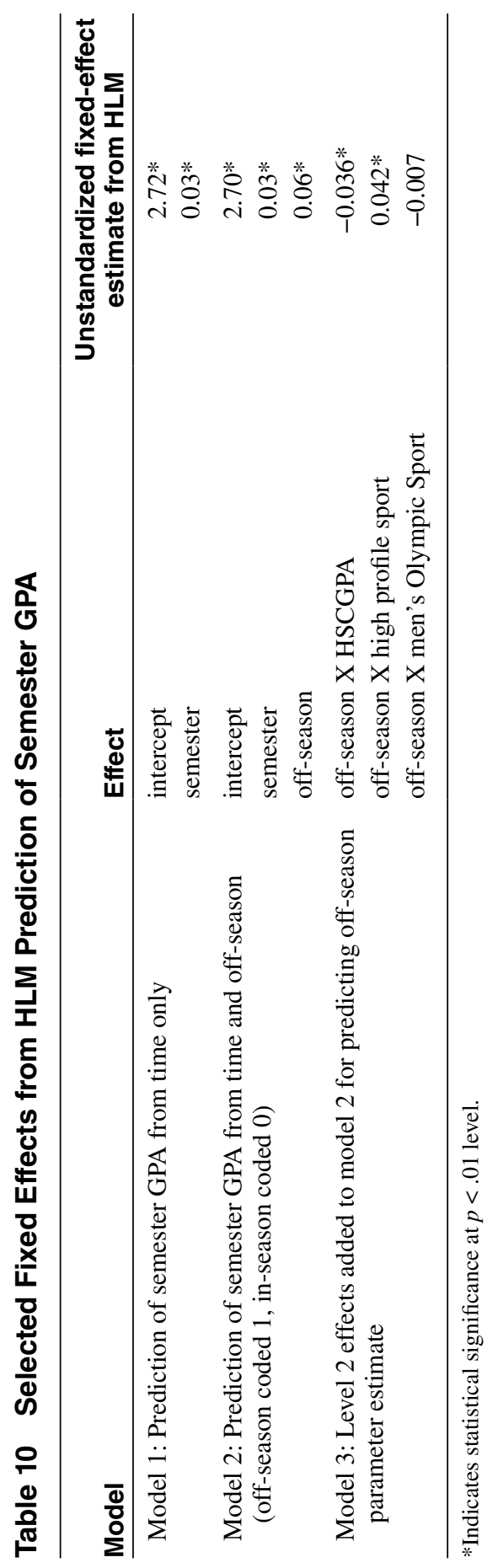


every one grade-point unit increase in HSCGPA. The trichotomous sport group variable was constructed as a pair of dummy variables. The first represented the in-season effect difference for men in high-profile sports (defined here as men's basketball, baseball and football) vs. female student-athletes and the second was used to contrast males in Olympic sports from female student-athletes. From the third model, the in-season effect is different for males in high-profile sports vs. females $(0.042$ grade points between groups, $[t(54762)=5.34, p<.01])$ but not men in Olympic sports when compared with females. In other words, the in-season vs. out-of-season GPA differences are enhanced for the males in high profile sports in comparison with the effects seen among all other student-athletes in Division I.

Figure 1 demonstrates these effects for four selected sports-baseball, football, men's tennis and women's tennis. The men's and women's tennis plots were chosen for display based simply on their representativeness of the effects found for men's Olympic and women's sports in the longitudinal modeling. The general upward trend of time on GPA is seen within each sport. The in-season vs. out-ofseason effect is noted to some degree in each sport but is much more pronounced in the high-profile sports of baseball and football. In baseball, the upward GPA trend is essentially interrupted on every even numbered (spring) semester; in football, a similar effect is seen during the odd numbered (fall) semesters.

Longitudinal models of credit-hour attainment. The same three models were run using credit hours earned as the dependent variable. Results were very similar to those for GPA and are shown in Table 11. When modeled over the course of the eight semesters, credit hours earned actually trend downward by 0.19 credits per term $(t(11236)=-29.50, p<.01)$. When the in-season effect was added in Model 2 , an effect of 0.57 credits earned was found $(t(62757)=31.96, p<.01)$. That is, student-athletes average roughly one-half of a credit hour less during their competitive seasons. The third model indicates that this effect is larger for students with lower HSCGPA. The credit hour differential decreases by approximately 0.13 credits for every one grade-point increase in HSCGPA $(t(56182)=-3.87, p$ $<.01)$. Again, males in high profile sports show a much larger differential $(0.42$ credits earned, $[t(55830)=9.47, p<.01])$ in comparison with female studentathletes. The men's Olympic effect was not statistically significant.

Figure 2 displays results graphically for the same four sports shown in the graph for GPA. Again, in-season effects are much more pronounced in the highprofile sports. Strong drops in credits earned are seen in all sports in year 4, likely related to a mixture of positive and negative issues. Specifically, prior unpublished NCAA research has indicated that some student-athletes who are close to completing the degree will take just enough hours to get the degree in their final semester. However, data also indicate that there is a significant subset of studentathletes who leave school as academic casualties as they complete their athletics eligibility. The dip in average credit attainment in Division I football begins as early as the seventh semester in these data. In addition to behavior related to exhausted eligibility academic departure, football student-athletes in Division I often take five years to complete their four years of eligibility. The observed credit drop may be attributable to student-athletes in this sport spreading out credits that might normally be earned in year four over their final two years on campus instead. 


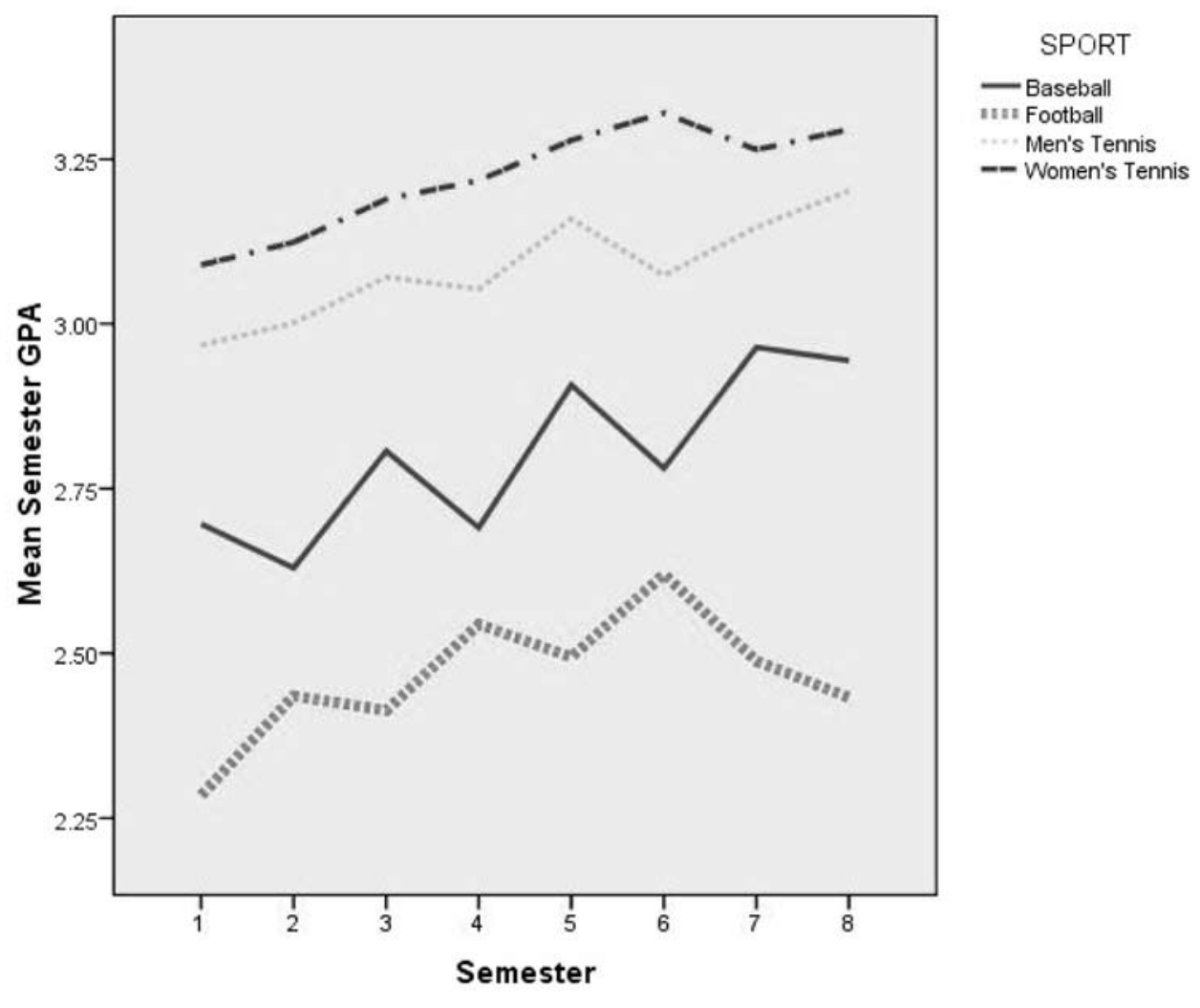

Figure 1 - Longitudinal trends of semester GPA for four select sports.

As displayed and analyzed, these data do not account for summer credits earned during college (a majority of Division I football and men's basketball players take summer classes at least once during college).

\section{Overall Discussion}

A number of academic initiatives have been undertaken by the NCAA's member colleges and universities over the past decade to enhance the academic performance of college student-athletes. A key component of these initiatives has been a significant expansion in academic data collection and analysis. Efforts such as the collection of graduation rates data in Divisions I and II have illustrated both positive (e.g., student-athletes graduate at higher rates than students in the general student body) and negative (e.g., student-athletes in high-profile sports tend to graduate at lower rates than other student-athletes) impacts of intercollegiate athletics participation on academic performance. Each of the authors has been involved in NCAA governance issues in varying capacities and can attest that 


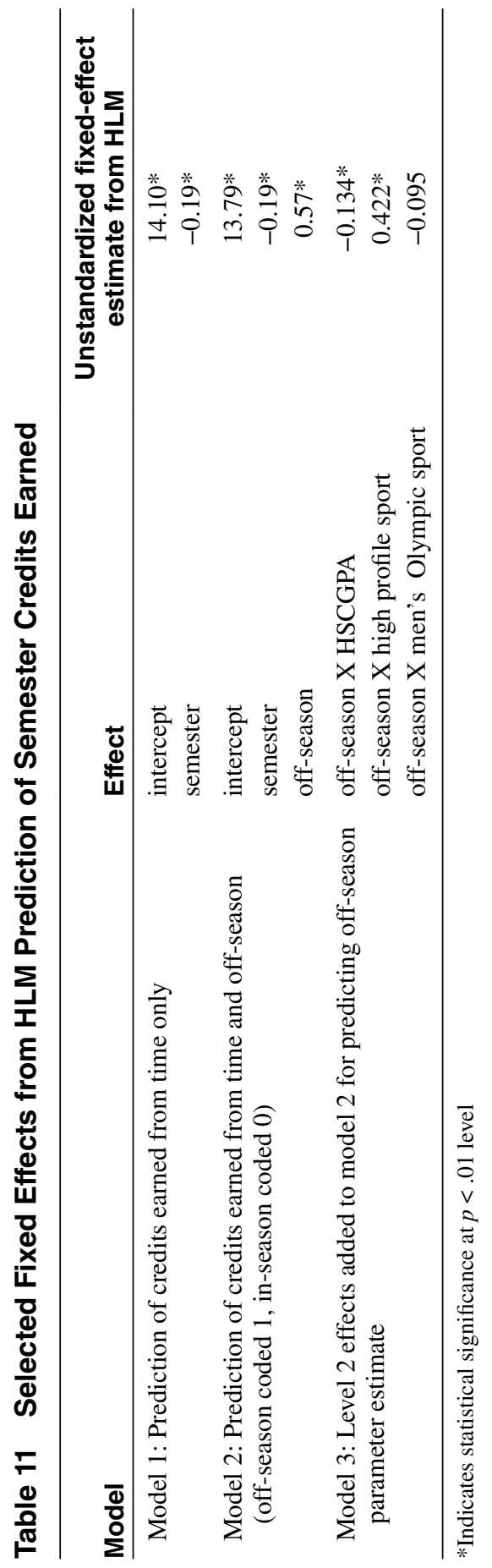




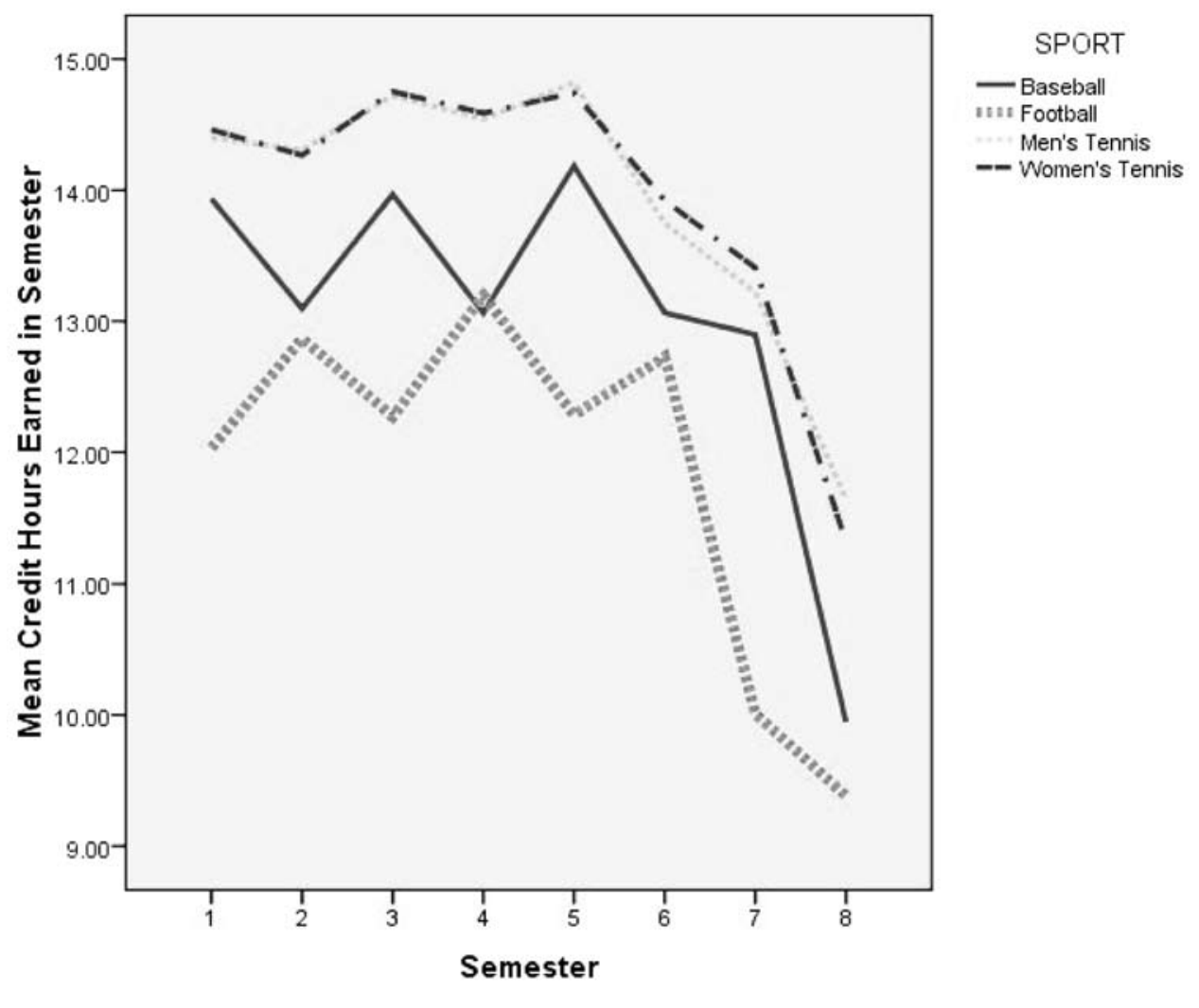

Figure 2 - Longitudinal trends of semester credit earned for four select sports.

today's NCAA leaders across all divisions actively seek out objective data on academic performance of student-athletes.

As such, these data collections have been instrumental in the crafting of NCAA academic initial eligibility and progress toward degree standards for student-athletes that take into account variables that have demonstrated effectiveness in predicting positive academic outcomes. Research-based benchmarks on these indicators (e.g., the location of the current Division I initial eligibility high school GPA-ACT/SAT sliding scale) are being developed based on large quantities of institutional data rather than conjecture or anecdote. These data collections have also allowed NCAA leaders to explore more nuanced data-driven policies. The creation of the Academic Progress Rate (APR) in Division I as a leading indicator of future graduation rate is a prime example. The development and implementation of the APR, a team-level "real-time" assessment of academic performance of student-athletes based on term-by-term eligibility and retention status, was possible only because objective term-by-term data were proactively requested, collected and analyzed. 
As new data are becoming available it is incumbent upon researchers in this field to challenge traditional assumptions that often go untested within college athletics. Think of the so-called "Moneyball" approach but in the classroom rather than on the playing field. One such notion that has been taken as an article of faith by many in the athletics community is that student-athletes perform better academically in their season of competition than they do outside of their season. The conventional wisdom has held that the structure provided by the athletics culture during one's season of competition leads to focused and enhanced academic efforts and, in turn, academic success. But, such ideas do not seem compatible with other data showing that increased athletics activity often corresponds with less time available for academics (Paskus, 2008).

Newly collected academic data from all divisions within the NCAA allowed for a test of this assertion in a rigorous way. The findings are quite clear-studentathletes in aggregate do not perform better academically within their season of competition than they do outside that season. Statistically, the differences between in-season and out-of-season performance are best classified as a small effect (Cohen, 1992), detectable in this study due to the large sample sizes available. However, select subgroups of student-athletes (e.g., those in high profile sports, student-athletes with low high school academic preparation, etc.) exhibit enhanced difficulties or slowed degree progress during times when they are actively competing. Those subgroups that show the most differences between their in-season and out-of-season performance are many of the same groups that have the lowest average graduation rates and APRs.

We cannot be certain about the causes of decreased in-season academic performances, but the time demands required of student-athletes in some sports are one possible moderating factor. Clearly the sports that seem to have the most significant in-season/out-of-season performance differences are also those with the highest time demands during the competitive season (e.g., baseball, football, men's basketball, women's softball; see Paskus, 2008). This "time demands" effect is not as clearly detectable in sports with a competitive season spanning large proportions of both fall and winter semesters (e.g., basketball and hockey) as it is in sports more compressed into one semester (e.g., baseball and softball). However, given the relationship that appears to exist between this seasonal effect (and other academic measures like APR) and competition-imposed time demands it might be time to reassess trends toward longer playing seasons or consider the necessity of summer school for some student-athletes. The idea that student-athletes benefit academically from longer seasons and more structured competition/ practice time probably exists among some coaches and administrators and the data simply do not support that contention.

The seasonal academic decreases were not limited to Division I programs that tend to require greater time commitments than seen in Divisions II and III; the effects appear to be present across all levels of college sport. Certainly a studentathlete who is committed to his/her sport or team will attempt to arrange a course schedule that does not unnecessarily interfere with athletic competition if the necessary academic work can be made up at a different time. From the data it appears that seasonal effects may not exist at all for some student-athletes. But, the results indicate that it is important to consider academic preparation as part of the issue. 
The Division I models showed that student-athletes who are less well prepared academically as they enter college are more likely to suffer seasonal drops in academic performances. This would have the highest impact in the sports of men's basketball and football, as those are the sports that typically have the lowest level of average academic preparation for their student-athletes. This issue is important because severe fluctuations in credits earned or GPA might be expected to impact not only eligibility for future seasons of competition but also likelihood of meeting standards of progress toward degree at that university. Eventually, this type of behavior will reduce the likelihood of student-athlete graduation.

Looking forward, it is hoped that other nuances in these small but potentially important effects can be extracted that better highlight correctable issues in particular sports within each division. Advanced modeling of student academic data that examines self-reported time commitments as one predictor of student-athlete academic trajectories is already underway and may provide additional insight. Other self-report data on student-athlete perceptions of their athletics and academic experiences is currently being collected in the NCAA's GOALS (Growth, Opportunities, Aspirations, and Learning of Students in college) and SCORE (Study of College Outcomes and Recent Experiences) studies and could help us determine whether college student-athletes see their commitments to athletics as being more self-imposed or structurally imposed. Initial information from these studies indicates that many student-athletes would devote even more time to sport if allowed while others clearly show the strain of balancing academic, athletic and personal commitments. Such research may assist in highlighting what forms of support, whether they be related to policy or personal assistance (e.g., counseling, advising, tutoring), might smooth out some of the bumps along the path to academic success and degree attainment.

\section{References}

Aries, E., McCarthy, D., Salovey, P., \& Banaji, M. (2004). A comparison of athletes and non-athletes at highly selective colleges: Academic performance and personal development. Research in Higher Education, 45(6), 577-602.

Bowen, W.G., \& Levin, S.A. (2003). Reclaiming the Game: College Sports and Educational Values. Princeton, NJ: Princeton University Press.

Bryk, A.S., \& Raudenbush, S.W. (2002). Hierarchical linear models: Applications and data analysis methods (2nd ed.). Thousand Oaks, CA: Sage Publications.

Cohen, J. (1992). A power primer. Psychological Bulletin, 112(1), 155-159.

Frost, R.E. (2001). Grade point averages of male and female student-athletes at public and private Division III institutions during traditional and nontraditional seasons. Unpublished master's thesis, Springfield College.

Jones, C.J., Livson, N., \& Peskin, H. (2003). Longitudinal hierarchical linear modeling analyses of California Psychological Inventory data from age 33 to 75: An examination of stability and change in adult personality. Journal of Personality Assessment, 80(3), 294-308.

Long, J.E., \& Caudill, S.B. (1991). The impact of participation in intercollegiate athletics on income and graduation. The Review of Economics and Statistics, 73(3), 525-531.

Maloney, M.T., \& McCormick, R.E. (1993). An examination of the role that intercollegiate athletic participation plays in academic achievement: Athletes' feats in the classroom. The Journal of Human Resources, 28(3), 555-570. 
McArdle, J.J., \& Hamagami, F. (1994). Logit and multilevel logit modeling studies of college graduation for 1984-85 freshmen student-athletes. Journal of the American Statistical Association, 89(427), 1107-1123.

National Collegiate Athletic Association. (2007, October 30). NCAA releases latest graduation data. [Press release]. www.ncaa.org/wps/ncaa?ContentID $=4852$.

Paskus, T. (2008, Spring). Study probes time allotments. Champion, 1(2), 18. Available at http://www.ncaachampionmagazine.org/archived/0408.

Robst, J., \& Keil, J. (2000). The relationship between athletic participation and academic performance: Evidence from NCAA Division III. Applied Economics, 32, 547-558.

Shulman, J.L., \& Bowen, W.G. (2001). The Game of Life: College Sports and Educational Values. Princeton, NJ: Princeton University Press.

Singer, J.D., \& Willett, J.B. (2003). Applied longitudinal data analysis: Modeling change and event occurrence. New York: Oxford University Press. 